\title{
Spectroscopy of Plutonium-Organic Complexes ${ }^{\star}$
}

\author{
Michael K. Richmann and Donald T. Reed \\ Argonne National Laboratory \\ 9700 South Cass Avenue \\ Argonne, IL 60439
}

RECEIVED

\author{
JAN 24995 \\ OSTI
}

\author{
Proceedings of \\ Materials Research Society Symposia \\ November 1995
}

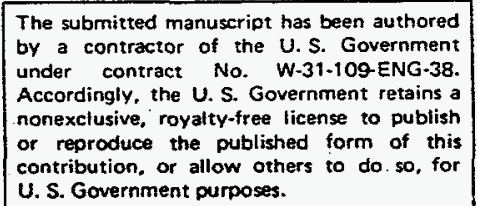

\begin{abstract}
DISCLAIMER
This report was prepared as an accouht of work sponsored by an agency of the United States Government. Neither the United States Government nor any agency thereof, nor any of their employees, makes any warranty, express or implied, or assumes any legal liability or responsibility for the accuracy, completeness, or usefulness of any information, apparatus, product, or process disclosed, or represents that its use would not infringe privately owned rights. Reference herein to any specific commercial product, process, or service by trade name, trademark, manufacturer, or otherwise does not necessarily constitute or imply its endorsement, recommendation, or favoring by the United States Government or any agency thereof. The views and opinions of authors expressed herein do not necessarily state or reflect those of the United States Government or any agency thereof.
\end{abstract}

*The authors wish to acknowledge the help of Dr. Ilham Al-Mahamid (LBL) for discussions pertaining to the speciation and redox behavior of plutonium in the PU-NTA system. This work was supported in part by the Co-Contaminants Chemistry Subprogram in the Subsurface Science Program, which is directed by Dr. Frank Wobber (DOE/OHER), and by internal funds at Argonne National Laboratory provided by the Arms Control and NonProliferation Program (Advanced Concepts Project). All the work was done under the U.S. Department of Energy contract W-31-109-ENG 38.

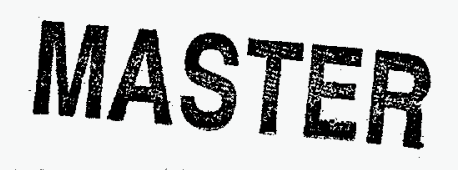




\title{
SPECTROSCOPY OF PLUTONIUM-ORGANIC COMPLEXES
}

\author{
M. K. RICHMANN, D. T. REED \\ Argonne National Laboratory, Argonne, II 60439
}

\begin{abstract}
Information on the spectroscopy of plutonium-organic complexes is needed to help establish the speciation of these complexes under environmentally relevant conditions. Laser photoacoustic spectroscopy (LPAS) and absorption spectrometry were used to characterize the Pu(TV)-citrate and $\mathrm{Pu}$ (IV)-nitrilotriacetic acid (NTA) complexes at concentrations of $10^{-3}-10^{-7} \underline{\mathrm{M}}$ in aqueous solution. Good agreement was observed between the band shape of the LPAS and absorption spectra for the $\mathrm{Pu}(\mathrm{IV})-\mathrm{NTA}$ complex. Agreement for the Pu(IV)-citrate complex was not quite as good. In both cases, a linear dependence of the LPAS signal on laser power and total concentration of the complexes was noted. This work is part of an ongoing research effort to study key subsurface interactions of plutonium-organic complexes.
\end{abstract}

\section{INTRODUCTION}

The effects of organic complexation on plutonium migration in the subsurface are of interest because organic complexants and radionuclides frequently co-exist as contaminants on DOE lands $[1,2]$. The presence of organics will affect the oxidation state, potentially increase the solubility of the radionuclide for a given oxidation state, and affect the bio-availability of the radionuclide. Organics typically of interest are naturally existing humic and fulvic acids and organic complexants used in the processing of actinides, such as nitrilotriacetic acid (NTA), citrate, oxalate, and ethylenediaminetetraacetic acid (EDTA). Reviews of both inorganic and organic complexation of actinides have been written [3-7].

Spectroscopic methods have been applied to a number of actinide-organic complexes to investigate their speciation. High sensitivity laser-based spectroscopic methods, such as laser photoacoustic spectroscopy, are being used to extend spectroscopic methods to the low concentrations expected to be more relevant to groundwater systems. In laser photoacoustic spectroscopy, a thermal acoustic wave is generated when a dissolved species undergoes a nonradiative transition from an excited state. As opposed to the radiative transition case where instrumentation such as photomultiplier tubes are able to detect photons, hardware such as a piezoelectric transducer (PZT) can amplify the thermal acoustic wave to resolvable levels. The signal resolved with the PZT is proportional to the extinction coefficient $(\epsilon)$ in the case where the excitedstate species undergoes primarily nonradiative decay and can be used to generate the absorption spectrum of the dissolved species. For the reasons just noted, it is important to characterize the LPAS response to verify that the signal obtained is proportional to the aqueous concentration of the actinide complex in the aqueous solution.

Herein, we report on the LPAS results obtained for the detection of the Pu(IV)-NTA and $\mathrm{Pu}(\mathrm{IV})$-citrate complexes in aqueous solution at very low concentrations $\left(10^{-5}-10^{-7} \mathrm{M}\right)$. This is an extension of past spectroscopic studies of plutonium systems [8-11] and is a part of current efforts to investigate the interactions of plutonium-organic complexes in microbial systems. 


\section{Preparation of the Pu-Organic Complex}

The Pu(IV)-NTA and Pu(IV)-citrate complexes were prepared well in advance of the LPAS analysis so that their stability and spectral characteristics could be established using absorption spectrometry. The complexes were made by reducing plutonium-239, typically in $50 \mathrm{mg}$ quantities, to $\mathrm{Pu}$ (III) by precipitation in hydrobromic acid and subsequent dilution in high purity water (18 $\mathrm{M} \Omega$ ). The $\mathrm{pH}$ was adjusted to $\mathrm{pH}-3$ to 4 with sodium hydroxide, and this solution was added to a either high-purity water or $0.01 \mathrm{M}$ PIPES (1,4-piperazinediethanesulfonic acid) buffer, at the desired $\mathrm{pH}$ (typically $\mathrm{pH}=5-7$ ), containing the desired amount of dissolved organic complexant. This resulted in a slow oxidation (hours to days) of the $\mathrm{Pu}(\mathrm{III})$ to form a $\mathrm{Pu}(\mathrm{IV})$-organic complex. We found this complex to be stable against decomposition for periods in excess of 6 months at ligand-to-metal ratios $>20$. The $\mathrm{Pu}$ (III) route was used to minimize plutonium hydrolysis, which competes with organic complexation at near-neutral $\mathrm{pH}$.

The higher-concentration samples (typically with $[\mathrm{Pu}]>10^{-5} \mathrm{M}$ ) were analyzed using a CARY-5 spectrometer. This state-of-the-art instrument is capable of monitoring absorption in the 200-3300 $\mathrm{nm}$ range while retaining linearity up to optical densities greater than 5 , and it has an overall sensitivity of $<0.001$ optical density units. Typically, this spectrometer was operated at a spectral resolution of $0.2 \mathrm{~nm}$. The sample was placed in gas-tight quartz cuvettes (1-cm square). Analyses were performed by placing the reference solution (organic solution) in the cuvette and obtaining a baseline over a period of $\sim 1 \mathrm{~h}$ to eliminate absorbance from the solvent and organic complexant. The same cell used to determine the baseline was rinsed with high-purity water three times and used for the plutonium-organic sample. Once sample stability was established, the solutions were transferred to the LPAS facility and analyzed. This gave us a same-sample analysis to directly compare the absorption and LPAS spectrum. The LPAS spectra were obtained as a function of plutonium concentration to determine the Beer-Lambert behavior of the complexes.

\section{Laser Photoacoustic Spectroscopy}

The LPAS apparatus used in this work is described in detail in our 1988 ANL topical report on speciation of radionuclides in natural groundwaters [8] and in Beitz et al. [9]. A block diagram of the experimental apparatus is shown in Figure 1. The excitation source is a Continuum Surelite II$20 \mathrm{Nd}$ :YAG laser combined with a Lambda Physik FL-3002 dye laser. In practice, the laser system is usually run at $10-20 \mathrm{~Hz}$ repetition rates and energies in the $6-12 \mathrm{~mJ} /$ pulse range to avoid sample heating effects.

The sample cells are constructed of a quartz cuvette (1-cm square) mounted in a thermostatted aluminum block. To minimize solution particulate effects, the sample was filtered with a $0.2 \mu \mathrm{m}$ filter and allowed to settle after emplacement. Typical settling times were less than $3 \mathrm{~h}$ for the "high" concentration samples $\left(\sim 10^{-5} \mathrm{M}\right)$, approximately $6 \mathrm{~h}$ for the $\sim 10^{-6} \mathrm{M}$ samples, and approximately one day for the $\sim 10^{-7} \mathrm{M}$ samples.

Averaging of the signal output was performed over as few as three to as many as several thousand laser pulses, depending on the desired signal-to-noise ratio. The dye laser energy was simultaneously recorded using a second boxcar. The resultant averaged output from the first boxcar and the output from the second boxcar were recorded in conjunction with user input tick marks for wavelength calibration and saved on a computer (AST 386, ANL modified SRS model SR265 data acquisition software). During analysis, the PZT response was divided by the laser energy to provide a normalized response. Also, the probe laser output was monitored as a function of wavelength and 


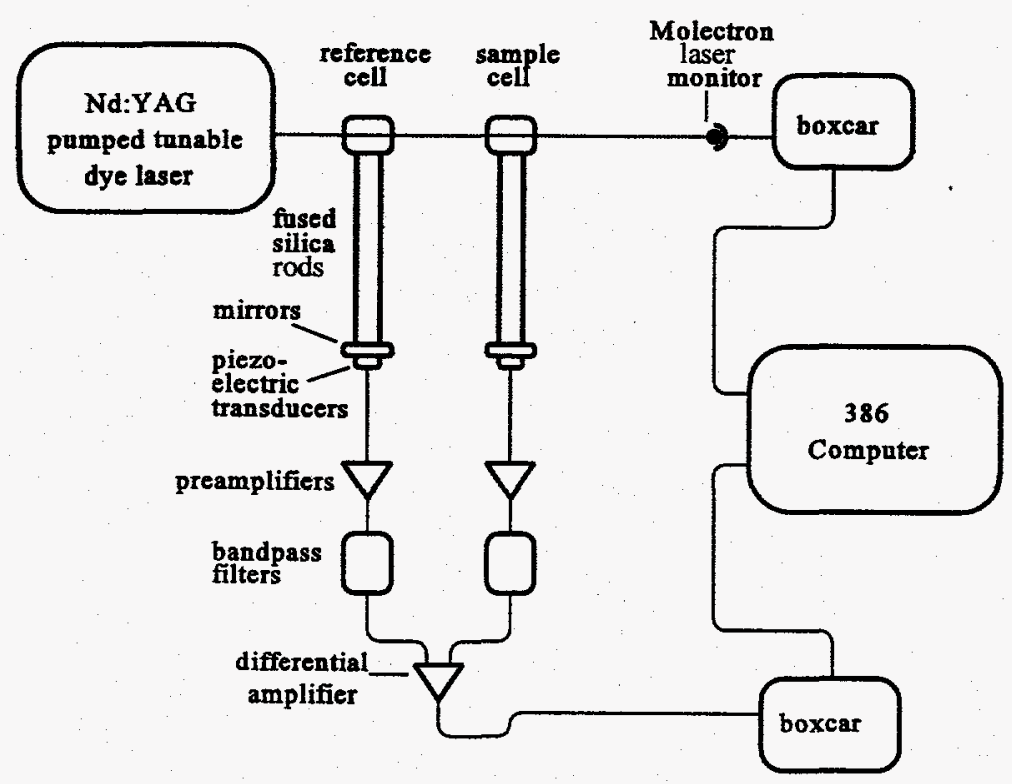

Figure 1 Laser photoacoustic experimental setup.

used to correct the amplitude of the actinide complex spectrum.

\section{RESULTS}

\section{Absorption Spectra of the Pu (IV)-NTA and Pu(TV)-Citrate Complex}

The absorption spectra for the Pu(IV)-NTA and Pu(IV)-citrate complexes, at $[\mathrm{Pu}] \sim 5 \times 10^{-5} \mathrm{M}$, are shown in Figure 2. These were obtained using the CARY-5 spectrometer and correspond to the highest concentration solutions analyzed with LPAS. The $490 \mathrm{~nm}$ to $520 \mathrm{~nm}$ region was best suited for analytical purposes, since it is in the blue-green region of the spectrum where 1) absorption due to water is the lowest and 2) the spectral feature of the two absorption bands reflects the nature of the organic complex. The absorption maxima of these two bands are $497.0 \pm 0.2 \mathrm{~nm}(\epsilon=128 \pm 32)$ and $506.0 \pm 0.2 \mathrm{~nm}(\epsilon=92 \pm 23)$ for the citrate complex and 497.0 $\pm 0.2(\epsilon=70 \pm 18)$ and 510.0 $\pm 0.2(\epsilon=20 \pm 5)$ for the NTA complex.

The citrate and NTA complexes were also monitored spectroscopically to determine their redox tendencies and their overall stability. We have noted that the Pu(IV)-citrate complex is the predominant complex formed and, once formed, is stable for periods of months. Preparation of $\mathrm{Pu}(\mathrm{III}, \mathrm{V}$, and VI)-citrate complexes, in air, results in the eventual reduction and/or oxidation of the plutonium species to form the Pu(IV) complex. For NTA [12], similar behavior was noted. In nearneutral $\mathrm{pH}$ solution, the Pu(IV)-NTA complexes were stable for periods of months at ligand-to-metal ratios $<2$ if the concentration of the plutonium complex was low enough $\left(<10^{-6} \mathrm{M}\right)$. At higher total plutonium concentrations, hydrolysis predominated, resulting in the eventual precipitation of the plutonium as a polymeric species.

\section{Power Dependence in LPAS Analysis}

The same plutonium-organic solutions analyzed by absorption spectrometry were used to 


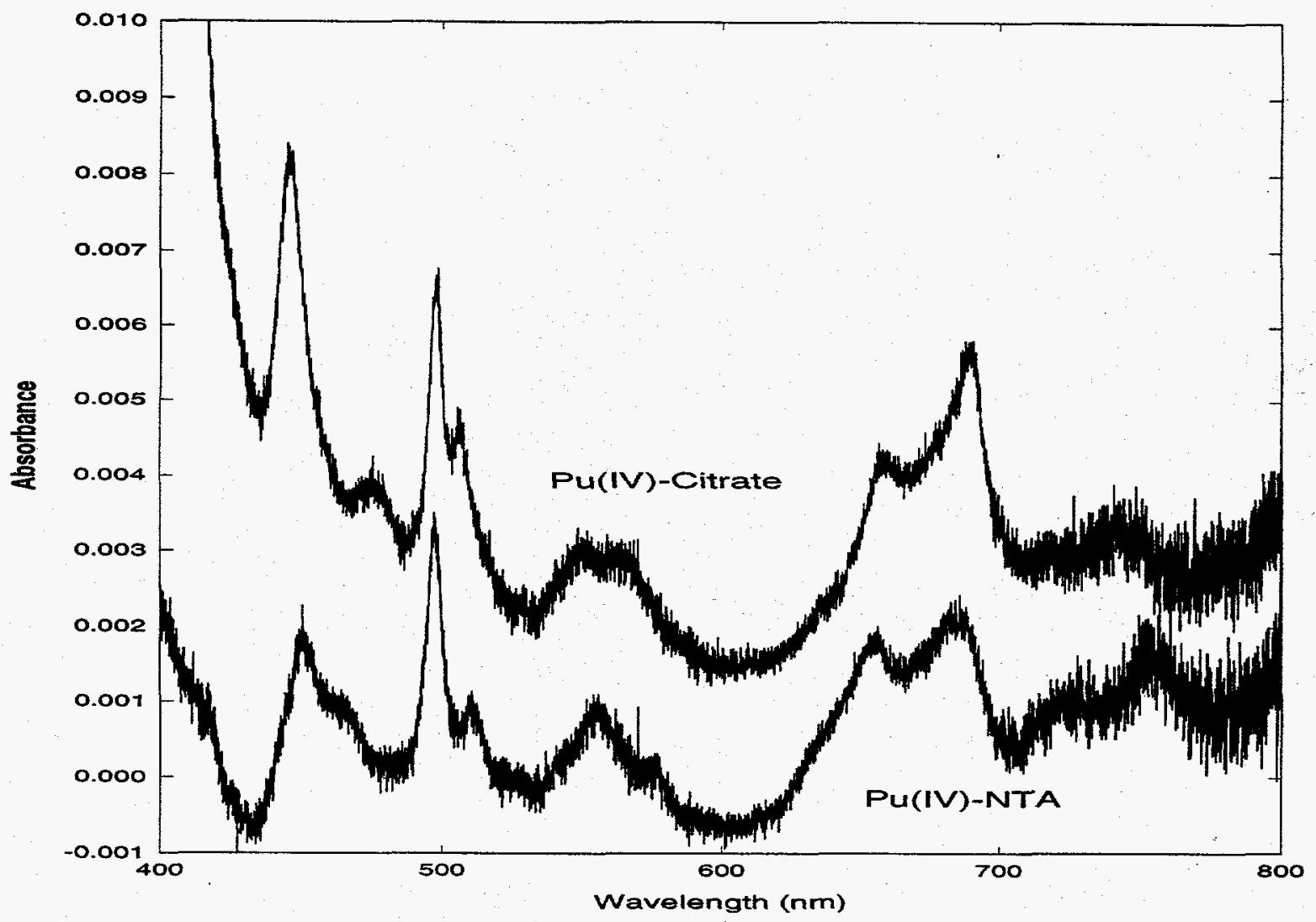

Figure 2 Absorption spectra of Pu(IV)-NTA and Pu(IV)-Citrate at $[\mathrm{Pu}]-5 \times 10^{-5} \underline{\mathrm{M}}$.

determine the effect of laser energy on the observed LPAS intensity. This was done at the maxima of the two absorption bands in the 490 to $520 \mathrm{~nm}$ region of the spectrum. The results of these analyses are shown in Figure 3.

The spectra were acquired using 18 laser shots per wavelength bin, in the 0 to $6 \mathrm{~mJ} /$ pulse power regime of the probe laser. Neutral density filters were used to adjust the power of the laser output. The resulting relative LPAS amplitude was linear in all cases investigated for both the citrate and NTA complexes. The slope of the power dependence was proportional to the extinction coefficients with linearity coefficients of $r^{2}>0.99$.

The observed linear dependence of the LPAS signal on the laser intensity indicated that no signal saturation was occurring up to a laser power of $6 \mathrm{~mJ} / \mathrm{pulse}$. We had shown this to be true up to $\sim 12$ $\mathrm{mJ} /$ pulse for the Pu(IV)-NTA complex in previous experimentation. This linearity indicated that the radiationless de-excitation of the excited state of both complexes was fast, relative to the conditions under which the data were acquired, and that the efficiency of the de-excitation process was unaffected by the changes in laser power. Differences in the laser power used to analyze samples can therefore be easily adjusted by reference to the power dependence curve. Lowering the plutoniumorganic concentration reduces the likelihood of signal saturation, making it less of an problem.

Beer-Lambert Dependence in LPAS Analysis

The Beer-Lambert dependence, i.e., linearity of the LPAS signal as a function of the concentration 

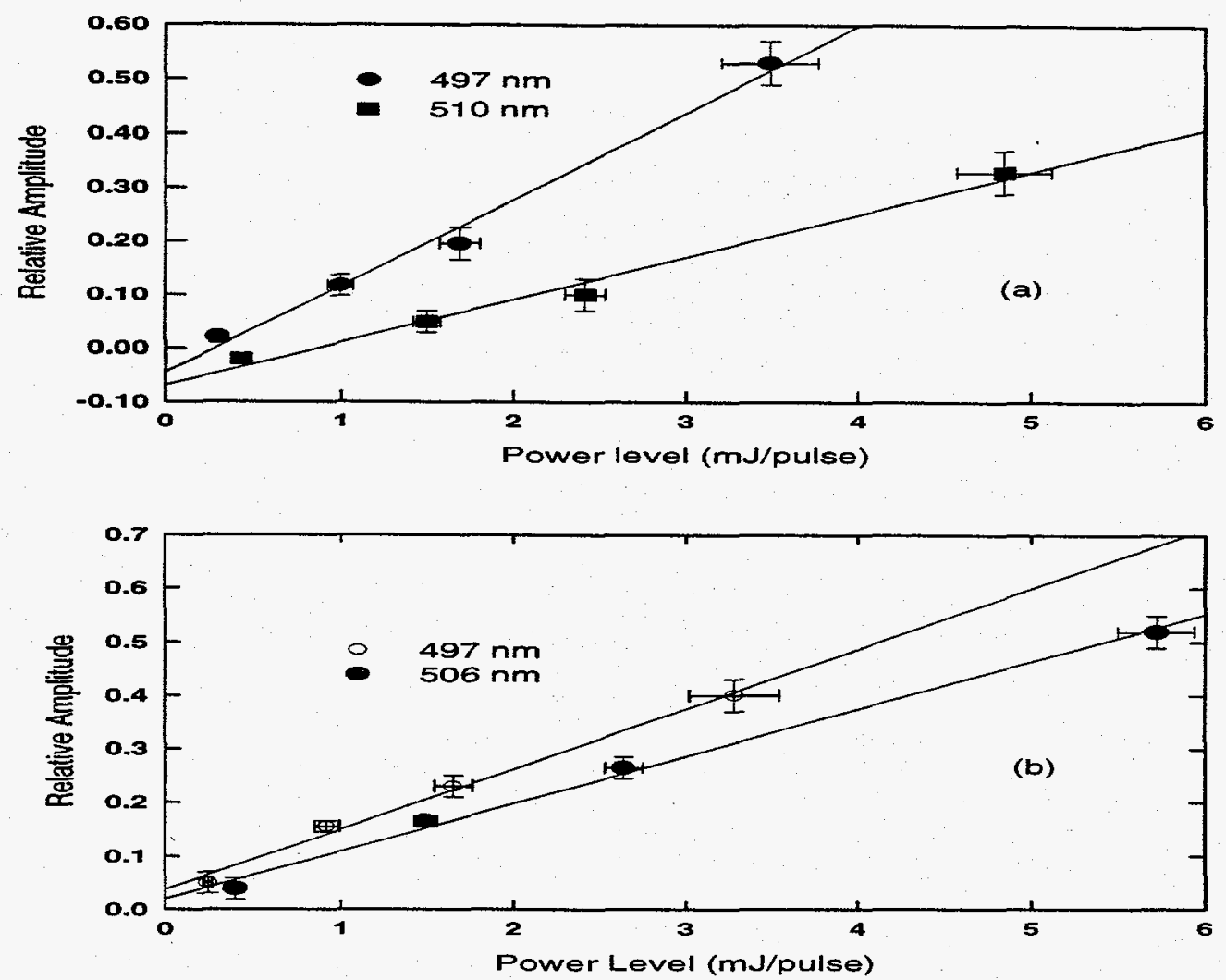

Figure 3 Power dependence of LPAS signal for (a) Pu(IV)-NTA and (b) Pu(IV)-Citrate at $[\mathrm{Pu}]=5 \times 10^{-5} \underline{\mathrm{M}}$.

of the plutonium-organic complex, was determined for both the Pu-NTA and Pu-citrate complex. This set of experiments was done to 1) determine whether the LPAS signal was proportional to the concentration of the plutonium-organic complex and 2) evaluate the sensitivity and linearity of the LPAS system to the complex of interest. The plutonium-organic complex was diluted by factors of 10 and 100 into the organic containing stock solution to give plutonium concentrations of $5 \times 10^{-5}$ $\underline{\mathrm{M}}, 5 \times 10^{-6} \underline{\mathrm{M}}$, and $5 \times 10^{-7} \underline{\mathrm{M}}$. The LPAS spectra were then obtained at fixed laser operating conditions. The resulting Beer-Lambert plots are shown in Figure 4.

The Beer-Lambert plot for the NTA complex was linear at both $497 \mathrm{~nm}$ and $510 \mathrm{~nm}$ (see Figure 4a). Correlation coefficients were $r^{2}>0.98$. The slopes at both wavelengths $(0.96 \pm 0.03$ at $497 \mathrm{~nm}$ and $0.86 \pm 0.04$ at $510 \mathrm{~nm}$ ) were not quite within experimental uncertainty of each other but were quite close, especially if one considers the differences in the extinction coefficients for each peak. This finding confirms that the LPAS signal amplitude at each wavelength was correlated to the concentration of the same complex. The projected detection limit of our LPAS system, based on the data in Figure 4, is $3 \times 10^{-7} \mathrm{M}$ for the NTA complex (S/N ratio > 10). Furthermore, we have utilized our LPAS system to monitor Pu-NTA concentrations less than $1 \times 10^{-7} \underline{\mathrm{M}}$ at higher laser energies and signals/wavelength bin.

The Beer-Lambert plots for the citrate complex were also linear at both $497 \mathrm{~nm}$ and $506 \mathrm{~nm}$ (see Figure $4 \mathrm{~b})$. Correlation coefficients were also $\mathrm{r}^{2}>0.98$, and both slopes $(0.83 \pm 0.10$ at $497 \mathrm{~nm}$ at $0.78 \pm 0.05$ at $506 \mathrm{~nm}$ ) were, again, not quite within experimental uncertainty of each other but were reasonable values given the extinction coefficients of the two peaks. It was, however, more difficult 

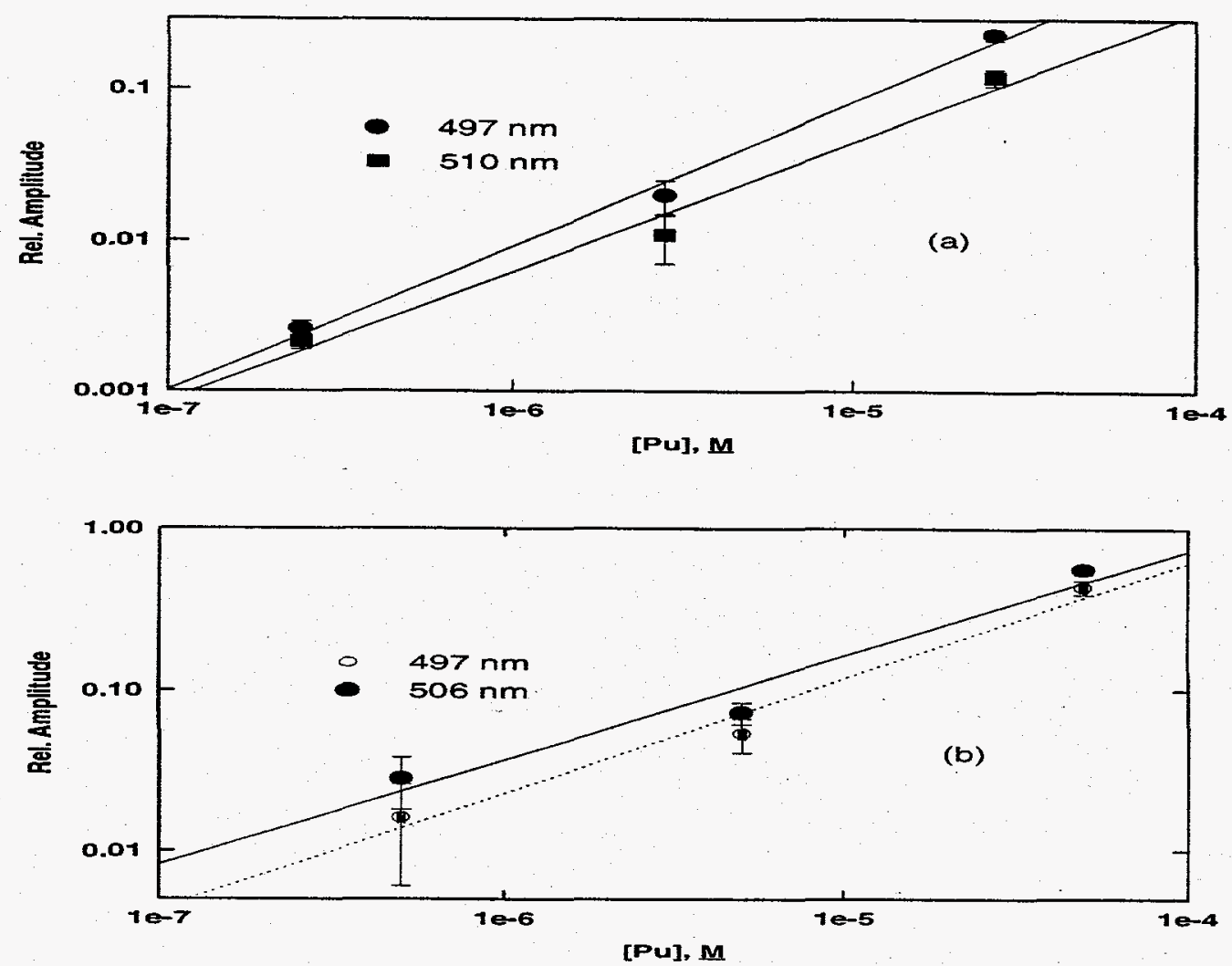

Figure 4 Beer-Lambert behavior of (a) Pu(IV)-NTA and (b) Pu(IV)-Citrate.

to obtain the lower concentration data than was the case for the NTA complex. This occurred because the citrate complex has a broader band shape, making it more difficult to experimentally establish the baseline at $497 \mathrm{~nm}$. Our estimated detection limit for the Pu-citrate complex is $3 \times 10^{-7}$ $\underline{\text { M. }}$

\section{Direct Comparison of Absorption and LPAS Spectra}

A comparison of the absorption and LPAS spectra is shown in Figure 5 for both the Pu-citrate and Pu-NTA complex. There was excellent agreement between the absorption and LPAS spectra for the plutonium-NTA spectrum. These two spectra were within the experimental uncertainty of each other. This result has been reproduced a number of times in our laboratory.

The matching of the LPAS and absorption spectra for the Pu-citrate complex was less satisfactory (see Figure 5b). There was good agreement for the band centered at $506 \mathrm{~nm}$. We have consistently, however, had more difficulty in matching the band shape at $497 \mathrm{~nm}$. Our past work has suggested that there may be some photophysical anomalies due to the photoactivity of citrate complexes $[13,14]$. The spectra, however, presented in Figure $5 \mathrm{~b}$ are barely within experimental agreement of each other, although there may be an $\sim 1 \mathrm{~nm}$ blue shift in the peak maxima. The increase at $\lambda<493$ $\mathrm{nm}$ in the LPAS spectrum is caused by the uncertainty introduced in subtracting out the baseline at wavelengths near the edge of the range of the laser dye used. Further work with a shorter wavelength laser dye is planned to more carefully evaluate the LPAS spectra of the $497 \mathrm{~nm}$ band. 

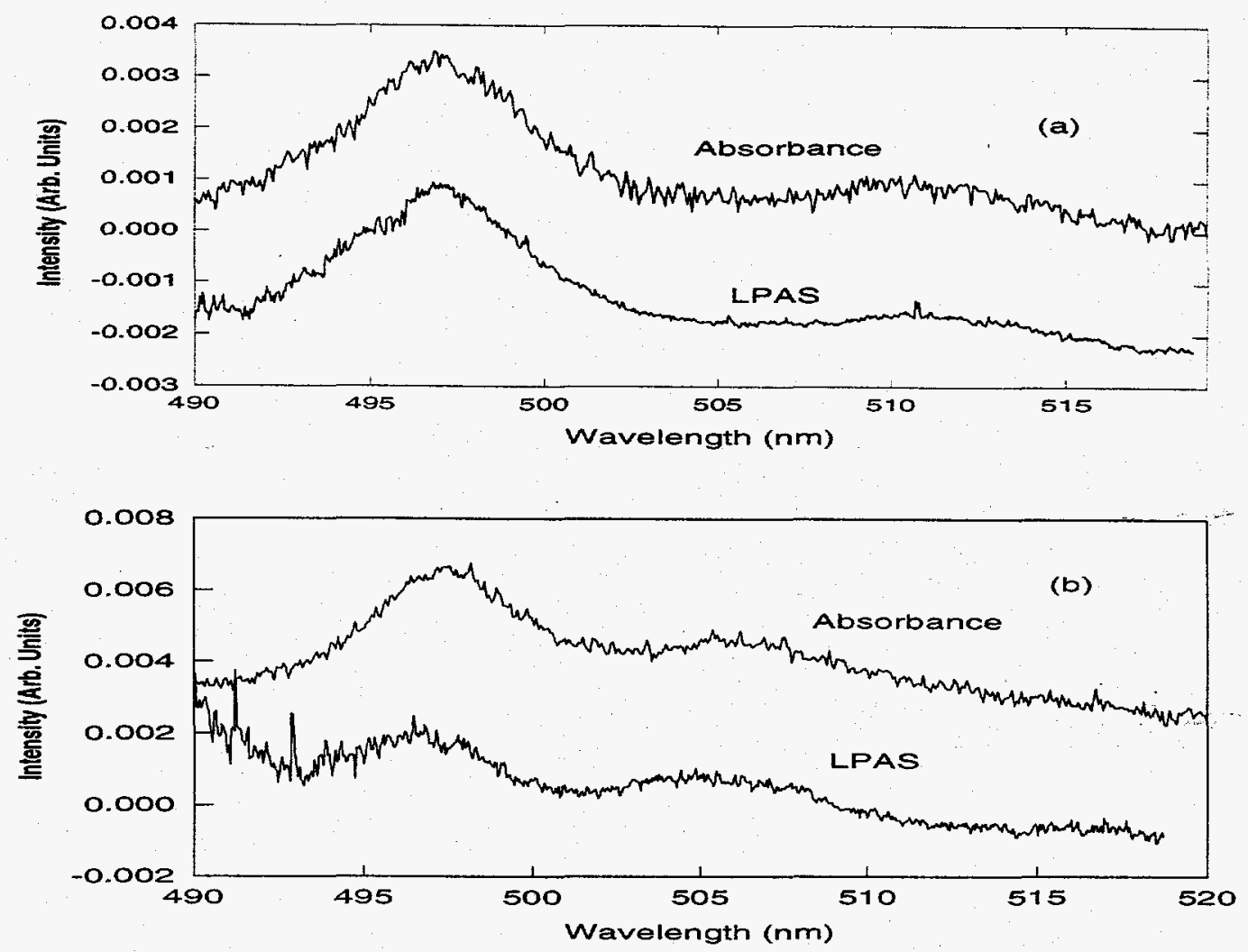

Figure 5 Comparison of absorption spectra against LPAS spectra for (a) Pu(IV)-NTA and (b) $\mathrm{Pu}(\mathrm{IV})$-Citrate at $[\mathrm{Pu}]=5 \times 10^{-5} \mathrm{M}$.

\section{CONCLUSIONS}

The LPAS spectra of the Pu-NTA and Pu-citrate complex were obtained as a function of laser power and plutonium concentration. For LPAS detection of the solutions with Pu-NTA complex, linearity was obtained with respect to the power dependence and Beer-Lambert plots, and the band shapes for the absorption and LPAS spectra showed good agreement. Complex concentrations $\sim 1$ $x 10^{-7} \underline{\mathrm{M}}$ could be readily detected, with perhaps lower concentrations achievable under ideal conditions. The LPAS detection of the Pu-citrate complex at very low concentrations was also demonstrated. The laser power dependence and Beer-Lambert plot was linear. It was not, however, possible to satisfactorily match the band shape of the $497 \mathrm{~nm}$ band. Analysis for the citrate complex using the $506 \mathrm{~nm}$ band should give quantitative results. Based on these data, we have shown that the LPAS technique can be used to detect and monitor the Pu-NTA and Pu-citrate complexes under welldefined conditions.

\section{ACKNOWLEDGMENT}

The authors wish to acknowledge the help of Dr. Itham Al- Mahamid (LBL) for discussions pertaining to the speciation and redox behavior of plutonium in the Pu-NTA system. This work was supported in part by the Co-Contaminants Chemistry Subprogram in the Subsurface Science Program, which is directed by Dr. Frank Wobber (DOE/OHER), and by internal funds at Argonne 
National Laboratory provided by the Arms Control and Non-Proliferation Program (Advanced Concepts Project). All the work was done under U.S. Department of Energy contract W-31-109ENG-38.

\section{REFERENCES}

1. D. T. Reed, J. M. Zachara, R. E. Wildung, and F. J. Wobber, in Scientific Basis of Nuclear Waste Management XIV (Mater. Res. Soc. Proc. 212, 1991) pp. 765-776.

2. U.S. Department of Energy (DOE), Subsurface Science Program: Program Overview and Research Abstracts. FY 1989-1990, DOE/ER-0432, U.S. Department of Energy, Washington, DC (1990).

3. R. G. Riley, and J. M. Zachara, Chemical Contaminants on DOE Lands and Selection of Contaminant Mixtures for Subsurface Science Research, DOE/ER-0574T. U.S. Department of Energy, Office of Health and Environmental Research, Washington, DC (1992).

4. S. Ahrland, J.O. Liljkenzin, and J. Rydberg in The Chemistry of the Actinides, edited by S. Ahrland (Pergammon Press, Oxford, 1973).

5. A. D. Jones and G. R. Choppin, Actinide Reviews 1, 311 (1969).

6. C. F. Baes and R. E. Mesmer, The Hydrolysis of Cations (John Wiley and Sons, New York, 1976).

7. T. W. Newton and J. C. Sullivan in "Actinide Carbonate Complexes in Aqueous Solution," Handbook of the Physics and Chemistry of the Actinides (1985), p. 387.

8. M. M. Doxtader, J. V. Beitz, D. T. Reed and J. K. Bates, Speciation of Radionuclides in Natural Groundwaters, Argonne National Laboratory Report ANL-88-5 (February 1988).

9. J. V. Beitz, M. M. Doxtader, V. A. Maroni, S. Okajima and D. T. Reed, Rev. Sci. Instrum. 61, 1395 (1990).

10. S. Okajima and D. T. Reed, Radiochim. Acta 60, 173 (1993).

11. S. Okajima, D. T. Reed, J. V. Beitz, C. A. Sabau, D. L. Bowers, Radiochim. Acta 52/53, 111 (1991).

12. Private communication with $\mathrm{H}$. Neitche.

13. C. J. Dodge and A. J. Francis, Environ. Sci. Tech. 28(7), 1300 (1994).

14. A. J. Francis, C. J. Dodge, S. Chatterjee, and M. F. Landry, Citrate Biodegradation - Mid-year Status Report, Brookhaven National Laboratory Report BNL-60830 (January 1994-June 1994) . 